University of Nebraska - Lincoln

DigitalCommons@University of Nebraska - Lincoln

Haskell Agricultural Laboratory (Northeast

Research and Extension Center)

Agricultural Research Division of IANR

2005

\title{
CASE STUDY: Tympanic Temperature and Behavior Associated with Moving Feedlot Cattle
}

\author{
T. L. Mader \\ University of Nebraska-Lincoln, tmader1@unl.edu
}

M. S. Davis

Koers-Turgeon Consulting Services, Inc., Salina, KS

W. M. Kreikemeier

Alltech Biotechnology, Dodge, NE

Follow this and additional works at: https://digitalcommons.unl.edu/ardhaskell

Part of the Agriculture Commons

Mader, T. L.; Davis, M. S.; and Kreikemeier, W. M., "CASE STUDY: Tympanic Temperature and Behavior Associated with Moving Feedlot Cattle" (2005). Haskell Agricultural Laboratory (Northeast Research and Extension Center). 14.

https://digitalcommons.unl.edu/ardhaskell/14

This Article is brought to you for free and open access by the Agricultural Research Division of IANR at DigitalCommons@University of Nebraska - Lincoln. It has been accepted for inclusion in Haskell Agricultural Laboratory (Northeast Research and Extension Center) by an authorized administrator of DigitalCommons@University of Nebraska - Lincoln. 


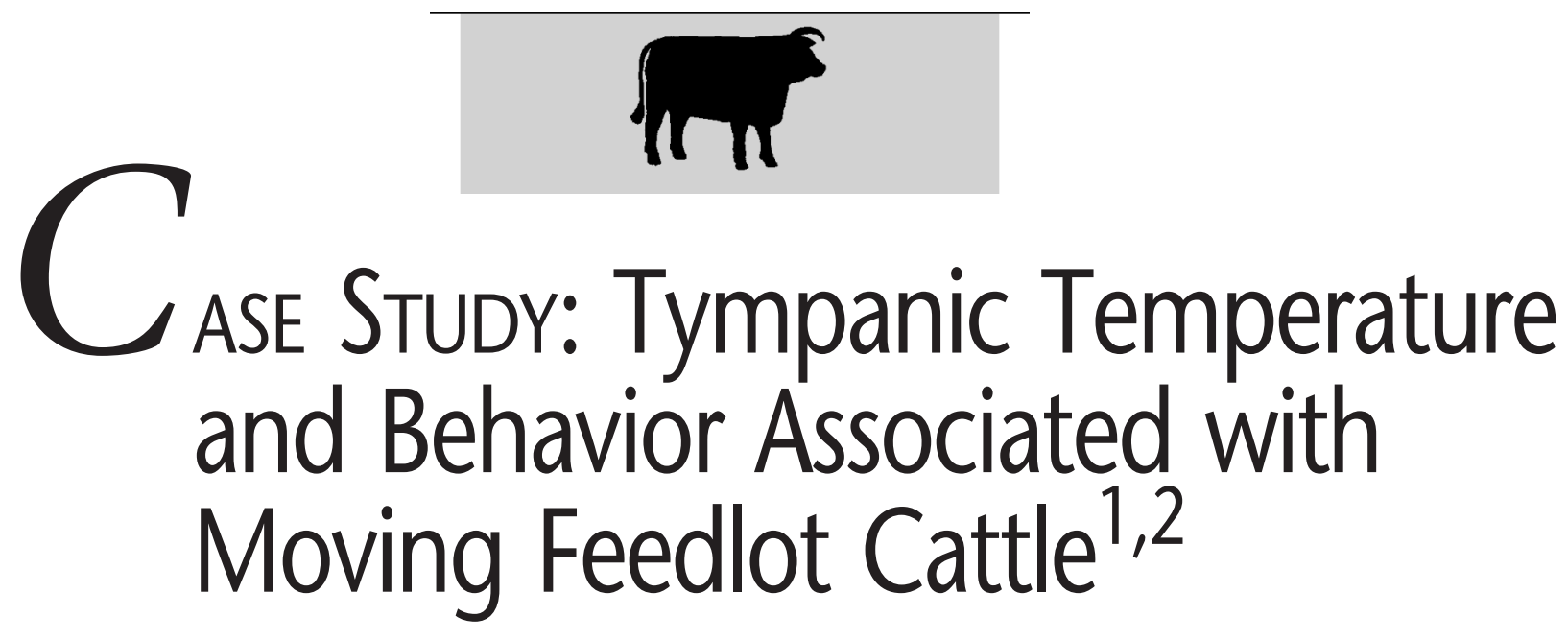

\author{
T. L. MADER*, PAS, M. S. DAVIS ${ }^{\dagger}$, PAS, and W. M. KREIKEMEIER ${ }^{\ddagger}$, PAS \\ *University of Nebraska, Department of Animal Science, Northeast Research and Extension Center, \\ Concord 68728, ${ }^{\dagger}$ Koers-Turgeon Consulting Services, Inc., Salina, KS 67401, and ${ }^{\ddagger}$ Alltech \\ Biotechnology, 151 8th Road, Dodge, NE 68633
}

\section{Abstract}

Body temperature is often used as an indicator of animal health status. In a series of handling experiments, tympanic temperatures (TT) were obtained in unrestrained feedlot cattle. In a January experiment $(B W=531 \pm 54 \mathrm{~kg})$, TT were increased $(P<0.05) 0.65^{\circ} \mathrm{C}$ and $0.58^{\circ} \mathrm{C}$ by moving cattle $600 \mathrm{~m}$ in morning and afternoon, respectively. Moving cattle ( $B W=456 \pm 67 \mathrm{~kg}) 150$ and $600 \mathrm{~m}$ in August elevated TT by $0.30^{\circ} \mathrm{C}$ and $0.67^{\circ} \mathrm{C}$, respectively. Moving cattle ( $B W=415 \pm 62 \mathrm{~kg}) 900 \mathrm{~m}$ in June elevated $(P<0.05)$ TT by $0.78^{\circ} \mathrm{C}$. Recovery TT was determined to be the time peak TT declined to levels equal to or below control (non-moved cattle) TT. Recovery times averaged 3.5 $h$ in the winter, but ranged from $<1 \mathrm{~h}$ to approximately $2 h$ in the spring and

\footnotetext{
${ }^{1} \mathrm{~A}$ contribution of the University of $\mathrm{Ne}$ braska Agricultural Research Division. Journals series 14420. Partial research support provided by the Biological and Environmental Research Program, U.S. Dep. of Energy, through the Great Plains Regional Center of the National Institute for Global Environmental Change (NIGEC) under Cooperative Agreement No. DE-FCO390ER61010.

${ }^{2}$ To whom correspondence should be addressed: tmader@unlnotes.unl.edu
}

summer experiments. Moving cattle decreased $(P<0.05)$ feed intake by approximately $1 \mathrm{~kg} / \mathrm{d}$ for up to $48 \mathrm{~h}$ after moving was completed. Moving cattle in the morning also decreased $(P<0.05)$ the number of animals resting in the afternoon (1400 h; Experiment 3) and increased $(P<0.05)$ the number of animals panting throughout the day (1100 and $1400 \mathrm{~h}$; Experiment 4). Effects of cattle movement on body temperature may need to be taken into account when evaluating animal health status. Conclusions based on these data would be most applicable for feedlot cattle exposed to warm and thermoneutral environmental conditions.

(Key Words: Feedlot, Body Temperature, Cattle, Handling.)

\section{Introduction}

Over 10 million head of cattle are fed in feedlots at any one time (USDA, 2003). Generally, feedlot cattle are vaccinated, treated for parasites, given a growth-promoting implant, and provided an eartag for identification within a few days of coming into the feedlot. A significant number of cattle are returned to the processing facilities during the feeding period to receive health care or to be reimplanted with a growth promotant. The effects of physical activity on body temperature are important if temperature is used as an indicator of health status. An elevated body temperature induced through physical activity or climatic factors could potentially provide false indicators of health status. Also, body temperature of cattle fed high energy diets in warm environments may already be elevated because of metabolic and climate-induced heat stress (Mader et al., 1999; Mader, 2003). The extent to which physical activity adds to body temperature change is unknown. Mader et al. (2002) and Davis et al. (2003) determined that tympanic temperatures (TT) can be easily obtained in free-roaming unrestrained cattle using a portable data logger attached to a thermistor. As a body temperature indicator, TT has been found to be an excellent measure of heat stress in feedlot cattle. In cattle exposed to hot climatic conditions, TT are very similar to rectal temperatures (Mader et al., 1999, 2002; Davis et al., 2003). The objective of these studies was to determine effects of moving cattle various distances in the feedyard on TT. In addition, effects of cattle movement on the proportion of cattle accessing feed and water were assessed. 


\section{Materials and Methods}

Four experiments were conducted using yearling Bos taurus feedlot cattle fed a high-energy finishing diet $\left(\mathrm{NE}_{\mathrm{g}}=1.43 \mathrm{mcal} / \mathrm{kg}\right)$. A general layout of the feedlot pens used in these experiments is provided by Mader et al. (1997a). The cattle working facilities were connected to the west side of pens that have access to overhead shelter. Entry and exit alleys for the processing facility were approximately $4 \mathrm{~m}$ wide. The entry alley exited into a $3.5-\mathrm{m}$ radius crowding pen that was connected to a hydraulic chute by a $12-\mathrm{m}$ long, $0.75-\mathrm{m}$ wide curved alleyway. The crowding pen, curved alleyway, and hydraulic chute were all under a roof. In all experiments, cattle were forced to move, but were allowed to move at a pace of their choosing. Cattle were moved to the working facilities, briefly delayed (approximately 5 min) in the curved alleyway and chute but not caught in the headgate, and then returned to the original pens. Facilities are located at $42^{\circ}$ $23^{\prime} \mathrm{N}$ latitude and $96^{\circ} 57^{\prime} \mathrm{W}$ longitude, with a mean elevation of 445 $\mathrm{m}$ above sea level.

In Experiment 1, which was conducted in January, five animals (BW $=531 \pm 54 \mathrm{~kg}$ ) from one pen were moved from the pen through the cattle working facilities and back into the pen. Cattle were moved at 0800 and $1500 \mathrm{~h}$. Total distance moved each time was approximately $600 \mathrm{~m}$ to and from the processing facilities (300 m one way). On d 2 and 4 , animals were moved. On d 1 and 3, animals were not moved. Animal TT was measured throughout the 4-d period.

In Experiment 2, which was conducted in August, eight animals (BW $=456 \pm 67 \mathrm{~kg}$ ) that had previously been randomly assigned to two pens (four head per pen) were utilized. On d 1 and 2, one pen of cattle was moved a total distance of approximately $150 \mathrm{~m}$, whereas the other pen was moved approximately $600 \mathrm{~m}$. Both pens of cattle were moved each day through the working facilities and back to their original pens. On d 3 and 4, cattle were allowed to rest and then moved again on $\mathrm{d} 5$ and 6 . Moving distance (short $v s$ long) assignments were reversed for each pen of cattle on the second set of moving days. Mean starting time for moving the cattle was $0906 \mathrm{~h}$.

In Experiment 3, which was conducted in June, 18 animals (BW = $415 \pm 62 \mathrm{~kg}$ ) were randomly assigned to three pens (six head per pen). On $2 \mathrm{~d}$ (d 1 and 2), cattle within respective pens were moved through the working facilities a total distance of approximately 300, 600, and $900 \mathrm{~m}$. In this experiment, daily feed intakes were measured plus the percentage of cattle that were recumbent, standing at bunk, and standing at waterer were recorded at 1000, 1100, 1200, 1300, and $1400 \mathrm{~h}$ for each day cattle were moved. Cattle were moved only once per day at approximately $0900 \mathrm{~h}$.

For each of the previously mentioned experiments, TT were obtained according to procedures described by Mader et al. (2002) and Davis et al. (2003). Individual animals were randomly selected within each pen to assess the effect of the imposed treatment on TT. In Experiment 1, TT was obtained from three animals in the pen. In Experiments 2 and 3, two and four animals per pen were selected for obtaining TT, respectively. Tympanic temperature was obtained once every $15 \mathrm{~min}$ in Experiment 1, every 2 min in Experiment 2, and every 1.5 min in Experiment 3.

In Experiment 4, which was conducted in June, 72 animals (BW = $436 \pm 24 \mathrm{~kg}$ ) previously assigned to eight pens (nine head per pen) were utilized to determine effects of moving cattle on feed intake, water intake, and animal behavior. In each of two 4-d periods, between 0850 and $0935 \mathrm{~h}$ of $\mathrm{d} 0$, four pens of cattle were moved a total distance of approximately $600 \mathrm{~m}$. The other four pens of cattle were not moved (con- trol). In each period, cattle were moved only one time. In the second period, the four pens of cattle previously moved were utilized as controls, and the previously non-moved four pens of cattle were moved. In addition to feed and water intake, behavior data, similar to that obtained in Experiment 3, were obtained at hourly intervals from 1000 to $1700 \mathrm{~h}$ for all pens of cattle during the day within each period that the pens of cattle were moved. In addition, the number of animals displaying signs of panting (respiration rate $>75$ breaths/min) was recorded.

For the first three experiments, ambient temperature for each study was obtained from the High Plains Climate Center automated weather station located $1.6 \mathrm{~km}$ northwest of the feedlot facilities. For the last experiment, weather data were obtained from a weather station located on the research site. All experiments reported herein were conducted at the University of Nebraska Northeast Research and Extension Center with the approval of the University of Nebraska-Lincoln Institutional Animal Care and Use Committee. All cattle were being fed ad libitum and had been at the research unit for a minimum of $60 \mathrm{~d}$. Cattle were managed and handled by experienced technicians with approval provided by the Institutional Animal Care and Use Committee.

Statistical Analysis. Tympanic temperature data were analyzed using PROC Mixed of SAS ${ }^{\circledR}$ (SAS Inst., Inc., Cary, NC) for repeated measures (Davis et al., 2003). Mean peak and mean post-peak low TT of moved cattle were compared with respective TT of non-moved cattle. In Experiment 1, TT on days cattle were moved were compared with $\mathrm{TT}$, at the corresponding time, of the same cattle on days they were not moved. Data were analyzed as a completely randomized design. In Experiment 2, TT data were analyzed as a two-period crossover design with day included as a replicate in the model. Pre-study TT was used as 
a covariant to adjust for differences in initial TT among animals. In Experiment 3 , TT data were analyzed as a completely randomized design. In Experiment 4, a two-period crossover design was utilized. Day and pen were included in the model. Feed and water intake data were analyzed using ANOVA procedures with period and pen included in the model. Behavior data were analyzed using chi-square. Within an experiment, differences among treatments were determined using Fisher's Protected LSD and the PDIFF option.

\section{Results and Discussion}

In Experiments 1, 2, 3, and 4, hourly ambient temperatures averaged $2.0 \pm 4.6^{\circ} \mathrm{C}, 20.4 \pm 3.6^{\circ} \mathrm{C}, 21.6$ $\pm 4.0^{\circ} \mathrm{C}$, and $21.9 \pm 3.9^{\circ} \mathrm{C}$, respectively. Weather and pen conditions were dry with no adverse cold or hot weather present. In Experiment 1 , on days cattle were moved $600 \mathrm{~m}$, TT were $0.77^{\circ} \mathrm{C}\left(38.29^{\circ} \mathrm{C}\right.$ vs $\left.39.06^{\circ} \mathrm{C}\right)$ and $0.73^{\circ} \mathrm{C}\left(38.57^{\circ} \mathrm{C}\right.$ vs $\left.39.30^{\circ} \mathrm{C}\right)$ greater $(P<0.05)$ in the morning and afternoon, respectively, than TT of the same cattle at corresponding times on days the cattle were not moved (Table 1). The process of moving cattle elevated TT immediately, most likely because of physical activity (D'Allaire and DeRoth, 1986). The TT during the nonmoved days remained low and in a fairly narrow temperature range. The times associated with the rise or peak in TT, as a result of moving, were 15 and 30 min in the morning and afternoon, respectively. Cattle TT returned to control (non-moved day) TT levels $3.5 \mathrm{~h}$ after peak TT was observed for both morning and afternoon moves.

In Experiment 2, when cattle were moved a long distance $(600 \mathrm{~m})$ in the summer, the rise in TT $(0.67$; $P<0.5)$ was similar to that found in the winter (Experiment 1) for cattle moved the same distance. For cattle moved a shorter distance $(150 \mathrm{~m})$, the rise in TT $\left(0.30^{\circ} \mathrm{C} ; P<0.05\right)$ was about one-half that of cattle moved

\section{TABLE 1. Effects of moving cattle through working facilities on tympanic temperature (TT) (Experiments 1 and 2).}

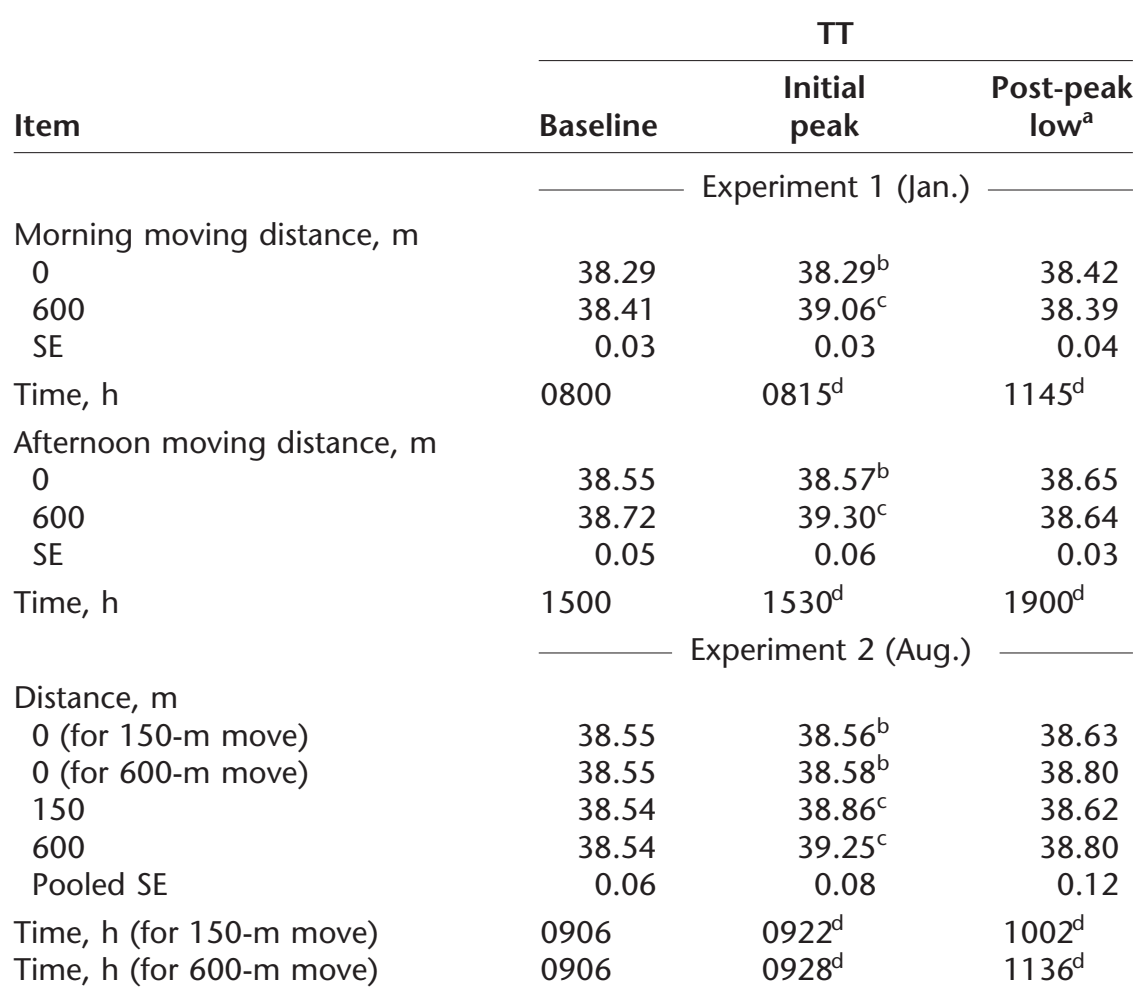

${ }^{\mathrm{a}}$ Corresponds to low point and/or point at which TT of moved cattle returns to that of TT of cattle that were not moved.

${ }^{\text {b}}$ Tympanic temperature of non-moved cattle at time peak TT occurred for moved cattle.

'Means between moved and non-moved cattle, within a column for respective trial or moving time, differ $(P<0.05)$.

${ }^{\mathrm{d}}$ Time-respective TT was recorded for cattle that were moved.

a greater distance. The decline in TT to levels found in cattle not moved was $\sim 2 \mathrm{~h}$ (0928 to $1136 \mathrm{~h})$ in cattle moved $600 \mathrm{~m}$ and $40 \mathrm{~min}$ in cattle moved $150 \mathrm{~m}$. Elevated body temperature, which is associated with hot climatic conditions, often contributes to a decline in feed intake (Mader et al., 1999). Returning body temperature to near normal levels as quickly as possible should allow intake to resume to normal levels. The more rapid return to baseline body temperature in the summer would be indicative of animals attempting to keep body temperature low as a buffer against climatic heat load, whereas the opposite response (a slow return to baseline) that was ob- served in the winter would possibly be indicative of animals attempting to keep body temperature elevated as a buffer against cold stress.

In Experiment 3, TT rises (0.68 to $0.78^{\circ} \mathrm{C}$ ) were similar regardless of distance moved. The rise was significant $(P<0.05)$ in all cases (Table 2$)$. Peak TT was reached between 31 and 42 min after moves were initiated. Post-peak lows, as in the previous experiment conducted in warmer weather, occurred approximately 2 to $2.5 \mathrm{~h}$ after moving began.

In research with humans, Kenny et al. (1999) reported that rectal temperature rose $1^{\circ} \mathrm{C}$ during $18 \mathrm{~min}$ of jogging on a treadmill. D'Allaire and 
TABLE 2. Effects of moving cattle through working facilities on tympanic temperature (TT) and behavior (Experiment 3; June).

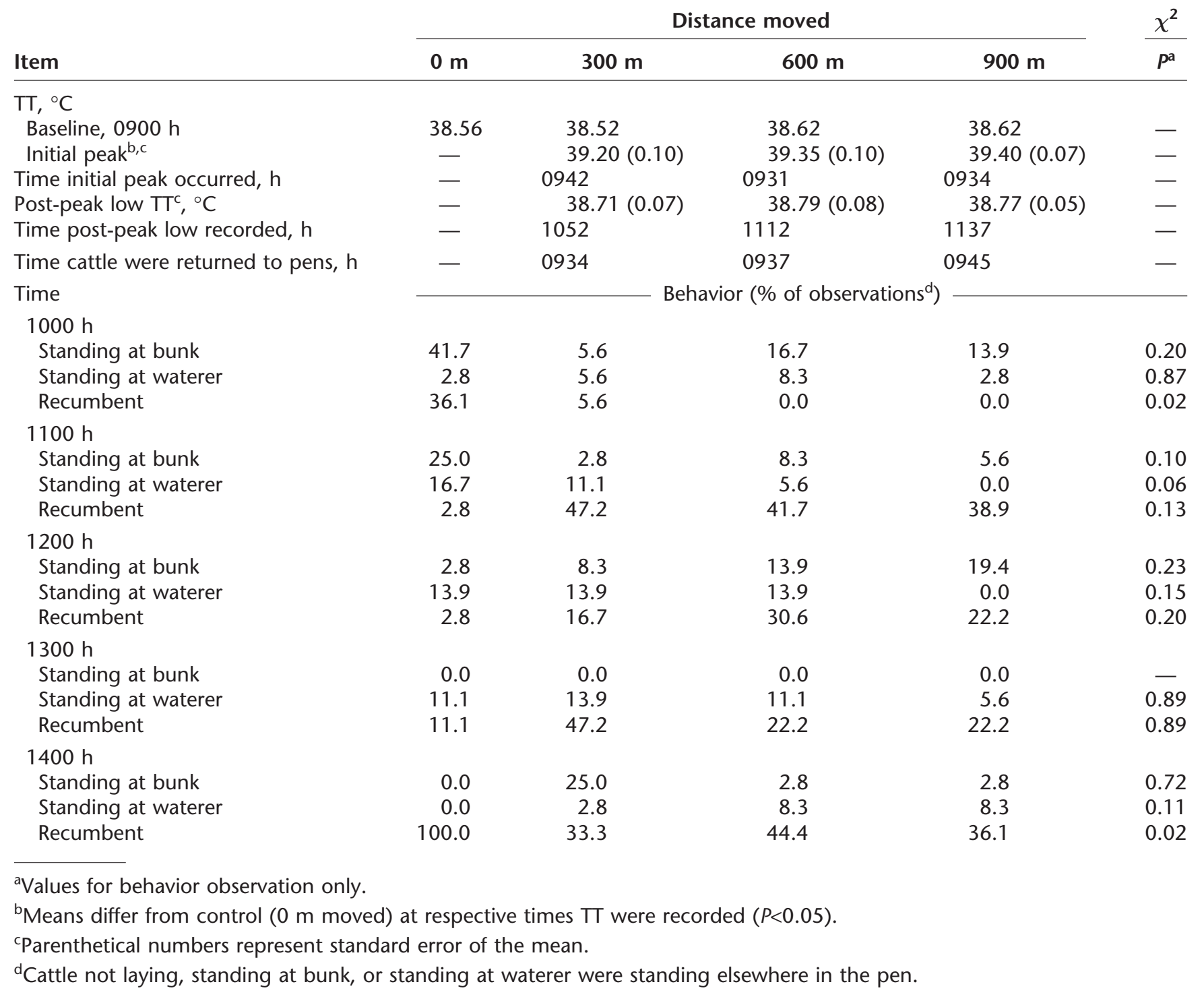

DeRoth (1986) submitted pigs to 10 min of treadmill $(1.8 \mathrm{~km} / \mathrm{h})$ exercise and found that rectal temperature of hyperthermic susceptible pigs rose nearly $1^{\circ} \mathrm{C}$ and $1.5^{\circ} \mathrm{C}$ at ambient temperatures of $14^{\circ} \mathrm{C}$ and $29^{\circ} \mathrm{C}$, respectively. At $14^{\circ} \mathrm{C}$, rectal temperatures reached a plateau almost immediately after exercise ceased; at $29^{\circ} \mathrm{C}$, rectal temperatures continued to rise for 5 min after exercise ceased. Fifteen minutes after exercise ceased, rectal temperatures declined under $14^{\circ} \mathrm{C}$ ambient temperature conditions but remained at peak levels at $29^{\circ} \mathrm{C}$ ambient temperature conditions. D'Allaire and Roth (1986) did not determine how long it took for body temperature to decline to preexercise levels. These data support the conclusion that body temperature of cattle will rise rapidly with exercise and may continue to rise even after exercise has ceased, particularly when warm or hot climatic conditions exist.

The percentage of cattle that were recumbent, standing at the bunk, or standing at water varied with time of day and previous distance moved
(Table 2). When compared with non-moved cattle observations, the number of cattle standing at the bunk tended $(P=0.10)$ to be reduced at $1100 \mathrm{~h}$. At $1200 \mathrm{~h}$, there was a trend $(P=0.23)$ for cattle that had been moved the farthest distance to have a greater percentage of the pen at the bunk. Interestingly, nonmoved cattle were all resting (laying) by $1400 \mathrm{~h}$ while only 33 to $36 \%$ of the moved cattle were resting $(P=0.02)$. In this experiment, numeric declines in DMI of 6.8, 13.6, and $18.2 \%$ were found for cattle 
moved 300, 600, and $900 \mathrm{~m}$, respectively, as a result of moving cattle when compared with pre-experiment DMI levels. Based on these observations, a follow-up experiment (Experiment 4) was conducted to obtain additional behavioral and feed intake data.

In Experiment 4 (Table 3), moving cattle $600 \mathrm{~m}$ did not significantly reduce DMI on the day cattle were moved. Moving did result in lessening DMI on the first $(P=0.06)$ and second $(P=0.04) \mathrm{d}$ after moving when compared with DMI of nonmoved cattle. However, moving cattle did not affect water intake. Generally, any activity that contributes to the animal experiencing heat stress should increase water intake or activity at the waterer (Mader et al., 1997b; Mader, 2003). Only at 1400 h, in Experiment 3 there was a tendency $(P=0.11)$ for this to have occurred. In Experiment 4, moving cattle resulted in cattle having elevated $(33.3 \%$ vs $13.9 \% ; P=0.01)$ respiration rate (panting) at 1000 and $1100 \mathrm{~h}$. At $1100 \mathrm{~h}$, an equal percentage of moved and non-moved cattle were at the waterer, but more cattle tended to be at the bunk if they had not been moved $(16.7 \%$ vs $5.6 \% ; P=0.09)$. At $1200 \mathrm{~h}$, a greater percentage $(30.6 \%$ vs $12.5 \%$; $P=$ $0.01)$ of the cattle that had not been moved were laying down. At $1600 \mathrm{~h}$, a greater percentage of the cattle that had been moved were panting (23.6\% vs 9.7\%; $P=0.03)$. This might have been due to more cattle that had previously been moved tending to approach the bunk (15.3\% vs $20.8 \%)$ and away from water (12.5\% vs 6.9\%), resulting in some added heat stress. At $1700 \mathrm{~h}$, almost no cattle (11.1\% vs $1.4 \% ; P=0.05)$ that had been moved were at the bunk.

These data were interpreted to suggest that moving cattle decreased $(P<0.05)$ feed intake for up to $2 \mathrm{~d}$ after moving was initiated. Moving cattle through working facilities requires an expenditure of energy, causing an elevation of body
TABLE 3. Effects of moving cattle through working facilities on DMI, water intake, and behavior (Experiment 4; June).

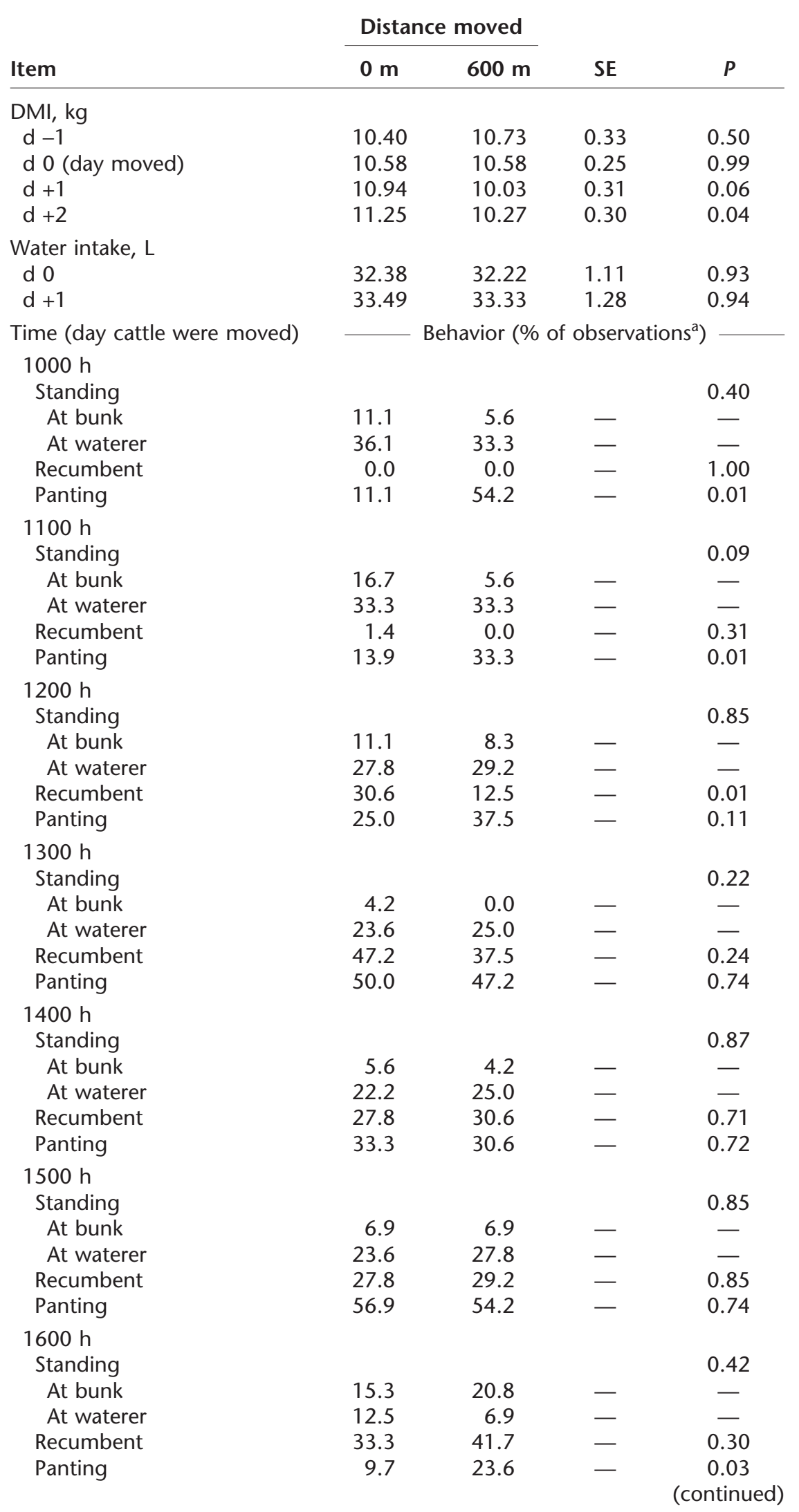


TABLE 3 (continued). Effects of moving cattle through working facilities on DMI, water intake, and behavior (Experiment 4; June).

\begin{tabular}{lrrrr} 
& \multicolumn{2}{c}{ Distance moved } & & \\
\cline { 2 - 3 } Item & $\mathbf{0 ~} \mathbf{~ m}$ & $\mathbf{6 0 0 ~ \mathbf { ~ }}$ & SE & $\boldsymbol{P}$ \\
\hline 1700 h & & & & \\
Standing & 11.1 & 1.4 & - & 0.05 \\
At bunk & 9.7 & 9.7 & - & - \\
At waterer & 41.7 & 43.1 & - & - \\
Recumbent & 15.3 & 15.3 & - & 0.87 \\
Panting & & & & 1.00
\end{tabular}

${ }^{a}$ Cattle not laying, standing at bunk, or standing at waterer were standing elsewhere in the pen; $P$ values for behavior data are based on $\chi^{2}$ analysis.

temperature. Effects of cattle movement and handling on body temperature need to be taken into account when processing cattle and(or) evaluating animal health status. Conclusions based on these data would be most applicable for feedlot cattle exposed to warm and thermoneutral environmental conditions. Similar findings may not be found under excessively hot or cold conditions or under conditions in which excessive air velocity exists and/or animals are wet from exposure to rain or snow. For example, moving cattle under conditions in which excessive cold stress is present could possibly result in cattle actually losing body heat, resulting in lessening of TT.

\section{Implications}

Body temperature is often used as an indicator of animal health status. In addition, body temperature can be used as a measure of heat stress. Moving cattle requires an expenditure of energy, causing an elevation of average body temperature between $0.3^{\circ} \mathrm{C}$ and $0.8^{\circ} \mathrm{C}$. Effects of cattle movement and handling on body temperature need to be taken into account when monitoring animal health status. Management strategies need to be considered that reduce the effects of moving stress on feed intake. Furthermore, minimal handling of cattle during hot days is recommended for maintaining optimum animal well-being and comfort.

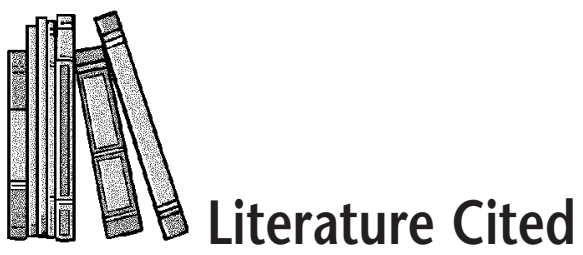

D'Allaire, S., and L. DeRoth. 1986. Physiological responses to treadmill exercise and ambient temperature in normal and malignant hyperthermia susceptible pigs. Can J. Vet. Res. 50:78.

Davis, M. S., T. L. Mader, S. M. Holt, and A. M. Parkhurst. 2003. Strategies to reduce feedlot cattle heat stress: Effects on tympanic temperature. J. Anim. Sci. 81:649.

Kenny, G. P., F. D. Reardon, J. S. Thoden, and G. G. Giesbrecht. 1999. Changes in exercise and post-exercise core temperature under different clothing conditions. Int. J. Biometeorol. 43:8.

Mader, T. L. 2003. Environmental stress in confined beef cattle. J. Anim. Sci. 81(E. Suppl. 2):E110.

Mader, T. L., J. M. Dahlquist, and J. B. Gaughan. 1997a. Wind protection effects and airflow patterns in outside feedlots. J. Anim. Sci. 75:26.

Mader, T. L., L. R. Fell, and M. J. McPhee. 1997b. Behavior response of non-Brahman cattle to shade in commercial feedlots. In Proc. 5th Int. Livest. Environ. Symp., Minneapolis, MN. p 795. Amer. Soc. Agric. Eng., St. Joseph, MI.

Mader, T. L., J. M. Gaughan, and B. A. Young. 1999. Feedlot diet roughage level of Hereford cattle exposed to excessive heat load. Prof. Anim. Sci. 15:53.

Mader, T. L., S. M. Holt, G. L. Hahn, M. S. Davis, and D. E. Spiers. 2002. Feeding strategies for managing heat load in feedlot cattle. J. Anim. Sci. 80:2373.

USDA. 2003. United States Cattle on Feed. Available http://www.usda.gov/nass/aggraphs/cof.htm. Accessed Jul. 23, 2003. 